\title{
ANALYSIS OF FENPROPATHRIN, LAMBDA-CYHALOTHRIN, AND CHLOROTHALONIL IN POTATO AND TOMATO SAMPLES USING GAS CHROMATOGRAPHY WITH AN ELECTRON CAPTURE DETECTOR
}

\author{
NADIA RAHMIANI, HARMITA*, HERMAN SURYADI \\ Department of Pharmacy, Faculty of Pharmacy, Universitas Indonesia, Depok, 16424, Indonesia. Email: igakadeharmita@gmail.com \\ Received: 12 April 2018, Revised and Accepted: 22 October 2018
}

\section{ABSTRACT}

Objective: This study aimed to analyze pesticide contents in potato and tomato samples.

Methods: In the present study, we determined the presence of the pesticides fenpropathrin, lambda-cyhalothrin, and chlorothalonil in conventional and organic potatoes and tomatoes using a gas chromatograph equipped with an electron capture detector and validated the associated methods. Acetone-based extraction was performed using the Dutch mini-Luke method with minimal weights and volumes.

Results: Validation tests showed a range of $70-120 \%$ and precision of $\leq 20 \%$, and linearity tests on the three standard pesticides gave $\mathrm{r}$ values of $\geq 0.9990$ for all three pesticides. Limit of detection and limit of quantitation values showed high sensitivity, although in vegetable sample analyses, none of the three pesticides were detected.

Conclusion: Our data show that the chosen method for analysis of the pesticides fenpropathrin, lambda-cyhalothrin, and chlorothalonil in potatoes and tomatoes is valid and that the marketed potatoes and tomatoes meet the SNI 7313: 2008 standard for "Maximum Limits of Pesticide Residues on Agricultural Products" and the associated Japanese standards.

Keywords: Gas chromatography, Electron capture detector, Organic vegetable, Non-organic vegetable, Fenpropathrin, Lambda-cyhalothrin, chlorothalonil, Dutch mini-Luke.

(C) 2018 The Authors. Published by Innovare Academic Sciences Pvt Ltd. This is an open access article under the CC BY license (http://creativecommons. org/licenses/by/4. 0/) DOI: http://dx.doi.org/10.22159/ijap.2018.v10s1.15

\section{INTRODUCTION}

Pesticides are used to eliminate pests so that agricultural harvests can be optimal and are also used to preserve woods and forestry products. Hence, human pesticide use has grown and developed considerably, and formerly used natural pesticides have been replaced with artificial agents [1].

Due to toxic effects in humans, animals, and the environment, bans have been placed on the use of several pesticides, including organochlorine agents such as aldrin, eldrin, DDT, and BHC [2]. Organochlorines are known persistent organic pollutants [3] that bioaccumulate and disperse into food chains. The fat solubility of these organochlorine pesticides is an important contributor to chronic toxicity. Moreover, DDT affects axonal transmission by decreasing sodium intake and inhibiting egress of potassium. Cyclodiene and hexachlorocyclohexane also inhibit chloride uptake in response to gamma-aminobutyric acid, which is a central nervous system mediator. As a consequence, these agents cause neuron hyperactivity, and death can occur within 24-72 h due to consequent breathing disturbances [4].

Despite their chronic toxic effects in humans and proven persistence in the environment, many organochlorines, such as chlorothalonil, have been used in Indonesia [5].

In addition to organochlorine, organophosphates, carbamates, and pyrethroids are used in Indonesia. Pyrethroid is a derivative of a molecule from chrysan flowers [6] and is classified into two types on the basis of the presence or absence of cyan $(\mathrm{C} \equiv \mathrm{N})$. Addition of cyan to this pesticide increases its insecticidal activity [7]. Cyan groups, including in fenpropathrin and lambda-cyhalothrin, can cause reversible paresthetic fever, numbness, tickling sensations of the skin, and nervous system perturbations [6]. Hence, evaluations of pesticide concentrations are crucial for food products. Several studies show health effects of pyrethroid residues in contaminated fruit and vegetables, and chronic consumption has a high potential to adversely affect humans [7].

Organic vegetables have become increasingly popular in recent years, on the basis of the assumptions of higher nutrition and the absence of toxic chemicals [8]. On the basis of a study by Yu and Yang in Singapore, 1 in 10 organic vegetables was not free of pesticide [9-11]. Hence, since fenpropathrin, lambda-cyhalothrin, and chlorothalonil are used in tomato and potato commodities [5], we tested samples of these vegetables.

Concentrations of these three pesticides were analyzed using a high activity liquid chromatography method with gas chromatography (GC) and a mass spectrometer (MS) detector and electron capture detector (ECD). The data herein show high sensitivity and selectivity of the ECD.

\section{MATERIALS AND METHODS}

\section{Materials}

Non-organic and organic potatoes and tomatoes of various brands were purchased in Depok, Jakarta, and Tangerang. The standard pesticides fenpropathrin, lambda-cyhalothrin, and chlorothalonil were purchased as 200-ppm solutions in acetone from National Plant Quality Assay Laboratory in Pasar Minggu, Jakarta, and were stored at $20^{\circ} \mathrm{C}$ in a refrigerator. Acetone pure absolute (p.a.; Merck, US), sodium sulfate anhydrate p.a. (Merck, US), petroleum ether p.a. (Merck, US Canada), dichloromethane p.a. (Merck, US), isooctane p.a. (Merck, US), and toluene p.a. (Merck, US) were purchased from respective suppliers.

\section{Analytical instrumentation}

Analyses were performed using a Shimadzu model GC-17A GC with an ECD, a 30-m capillary column of $0.25 \mathrm{~mm}$ in diameter and $0.25 \mu \mathrm{m}$ in 
film thickness, nitrogen carrier gas, GC solution, a 5.0- $\mu \mathrm{L}$ microsyringe (Hamilton Co., Nevada, USA), scales, vortex, centrifuge, blender, evaporator, and glass tools.

\section{Procedures}

\section{Preparation of solutions}

Standard primary solutions were prepared by evaporating standard pesticide (200 ppm) solutions of up to $1 \mathrm{ml}$ under a flow of nitrogen gas in a $60^{\circ} \mathrm{C}$ evaporator over $10 \mathrm{~min}$. Pesticide residues were then dissolved in 10-ml aliquots of isooctane-toluene (9:1) to produce solutions of $20 \mathrm{ppm}$ as described by Lozano et al. [12,13].

The calibration curve of fenpropathrin standard liquid was prepared by placing 2.0-, 2.5-, 3.0-, 3.5-, 4.0-, and 4.5-ml aliquots of $100-\mathrm{ppm}$ solutions into six 10-ml glass measuring flasks and filling to volume with isooctane-toluene $(9: 1)$. Standard fenpropathrin concentrations were of $20,25,30,35,40$, and $45 \mathrm{ppb}$. Using 100-ppb cyhalothrin standard solution, we prepared standard solutions of 15, 20, 25, 30, and 40 ppb. Similarly, from 100 -ppb cyhalothrin solution, we prepared solutions at $5,10,15,20,25$, and $30 \mathrm{ppb}$

\section{Analysis conditions}

Analyses were performed with an injection volume of $1 \mu \mathrm{L}$ and an injector and detector temperature of $300^{\circ} \mathrm{C}$ using nitrogen as the carrier gas at $1 \mathrm{ml} / \mathrm{min}$. The oven temperature program was $80^{\circ} \mathrm{C}$ for $1 \mathrm{~min}$, followed by increases to $180^{\circ} \mathrm{C}$ at $25^{\circ} \mathrm{C} / \mathrm{min}$ and then to $280^{\circ} \mathrm{C}$ at $8^{\circ} \mathrm{C} / \mathrm{min}$ and finally to $300^{\circ} \mathrm{C}$ at $30^{\circ} \mathrm{C} / \mathrm{min}$. The temperature was then maintained at $300^{\circ} \mathrm{C}$ for $3.17 \mathrm{~min}$. The total time of analysis was about 22 min (Lozano et al., 2016).

\section{Method validation}

Linearity tests were performed by injecting six standard solutions of various concentrations. Data were then analyzed using linear regression of concentration versus area, and corresponding $r$ values were generated. Limit of detection (LOD) and limit of quantitation (LOQ) were calculated from the calibration curve [14].

Precision tests and extractions were conducted as described by Lozano et al. at three concentrations $[12,13]$. Simulations were performed with organic vegetables as matrix, and pesticide-free status was confirmed. The requirements of this study were $\mathrm{f} 70 \%-120 \%$ and percentage VC $<20 \%$ [11].

Standard solutions of $200 \mathrm{ppm}$ in acetone were diluted to $100 \mathrm{ppb}$ and were added to the matrix and then extracted as described previously [12,13]. Fenpropathrin was diluted in acetone to 80, 140, and $180 \mathrm{ppb}$. Subsequently, 6.0-g samples were weighed into 18 different centrifuge tubes and 5-ml aliquots of 20-ppb fenpropathrin solution were added to the first six tubes, 5-ml aliquots of 35-ppb fenpropathrin were added to glass tubes 7-12, 5-ml aliquots of 45$\mathrm{ppb}$ fenpropathrin in acetone were added to tubes 13-18, and all tubes were shaken and then left standing for $5 \mathrm{~min} .6 \mathrm{~g}$ of anhydrate $\mathrm{Na} 2 \mathrm{SO} 4$ and $3 \mathrm{ml}$ of acetone were then added, and all tubes were centrifuged for $30 \mathrm{~s}$ at $1500 \mathrm{rpm}$ (extraction stage). Thereafter, 8-ml aliquots of petroleum ether and 4-ml aliquots of dichloromethane were added, and the tubes were centrifuged again for $30 \mathrm{~s}$ at $1500 \mathrm{rpm}$ (partition stage). After centrifuging at $3300 \mathrm{rpm}$ for $3 \mathrm{~min}$, up to $3 \mathrm{ml}$ of the upper layers were taken and evaporated in a water boiler with increasing temperature from $45 \mathrm{C}$ until extracts were dry. Residues were diluted in $0.9 \mathrm{ml}$ of isooctane-toluene (9:1) and were analyzed under the described conditions. The resulting fenpropathrin solutions had concentrations of 20,35, and $45 \mathrm{ppb}$, and 1-, 10-, and 40-ppb lambda-cyhalothrin, and 5-, 20-, and 30-ppb chlorothalonil solutions were processed as described above.

\section{Sample preparation}

$1 \mathrm{~km}$ samples of conventional and organic potatoes and tomatoes of differing brands were purchased in Depok, Jakarta, and Tangerang. Extraction procedures were performed according to the study by Lozano et al. but with a volume: weight ratio of $2: 5[12,13]$. Vegetables were cut and blended, and 0.1-g samples were placed in centrifuge tubes with $8 \mathrm{ml}$ of acetone and $6 \mathrm{~g}$ of anhydrate Na2SO4. After centrifuging at $1500 \mathrm{rpm}$ for $30 \mathrm{~s}$ (extraction stage), 8-ml aliquots of petroleum ether and 4-ml aliquots of dichloromethane were added and the tubes were centrifuged again for $30 \mathrm{~s}$ at $1500 \mathrm{rpm}$ (partition stage) and then at $3300 \mathrm{rpm}$ for $3 \mathrm{~min}$. Up to $3-\mathrm{ml}$ upper layers were then taken and evaporated in a water bath with increasing temperature from $45^{\circ} \mathrm{C}$ to $63^{\circ} \mathrm{C}$ until residues were dry. Residues were finally dissolved in $0.9-\mathrm{ml}$ aliquots of isooctane-toluene (9:1) and were analyzed as described above.

\section{Establishment of samples}

Qualitative and quantitative analyses were performed with $1-\mu \mathrm{L}$ samples in triplicate using the described analysis conditions.

\section{RESULTS AND DISCUSSION}

\section{Condition analysis}

Analyses were performed as described by Lozano et al. with slight modifications [13]. Briefly, the oven temperature program was $80^{\circ} \mathrm{C}$ for $1 \mathrm{~min}$, followed by increasing temperature to $180^{\circ} \mathrm{C}$ at $25^{\circ} \mathrm{C} / \mathrm{min}$, to $280^{\circ} \mathrm{C}$ at $8^{\circ} \mathrm{C} / \mathrm{min}$, and then to $300^{\circ} \mathrm{C}$ at $30^{\circ} \mathrm{C} / \mathrm{min}$, which was maintained for $3.17 \mathrm{~min}$. The total analysis time was about $22 \mathrm{~min}$. Comparisons with the analysis conditions described by Lozano et al. are listed in Table $1[12,13]$

\section{Establishment of retention times}

After injecting fenpropathrin, lambda-cyhalothrin, and chlorothalonil at $20 \mathrm{ppm}$, retention times were 18.363, 19.278, and $10.851 \mathrm{~min}$, respectively.

\section{Validation of analysis methods Linearity tests}

Linearity was tested using fenpropathrin at 20,25, 30, 35, 40, and 45 ppb. Regression analysis of concentration versus area gave the linear equation $y=583.57 x-4418.2$ with an $\mathrm{r}$ value of 0.9994 . Linearity tests for lambda-cyhalothrin were performed at 10, 15, 20, 25, 30, and 40 $\mathrm{ppb}$ and gave the equation $y=1879.4 x+12787$ with an $\mathrm{r}$ value of 0.9992 . For chlorothalonil at $5,10,15,20,25$, and $30 \mathrm{ppb}$, the linear equation $y=1061.7 x-177.8$ was generated with an $\mathrm{r}$ value of 0.9993 .

Table 1: Differences between analysis conditions between Lozano et al. and the present study

\begin{tabular}{lll}
\hline Notes & Lozano et al. & This study \\
\hline Tools & Bruker $436 \mathrm{GC}$ & Shimadzu GC-17A \\
Detector & MS & ECD \\
Columns & Capillary columns $30 \mathrm{~m}$ in length and $0.25 \mathrm{~mm}$ in & Capillary columns $30 \mathrm{~m}$ in length and $0.25 \mathrm{~mm}$ in \\
& diameter, $0.25-\mu \mathrm{m}$ film thickness with VF-5 idle phase & diameter, $0.25-\mu \mathrm{m}$ film thickness with DB-5 idle phase \\
Media phase & Helium with argon & Nitrogen \\
Injector & Autosampler Variant CP-8400 & (manual) \\
Injection volume & $5 \mu \mathrm{L}$ & $1 \mu \mathrm{L}$ \\
Analysis methods & Internal standard & External standard \\
\hline
\end{tabular}

GC: Gas chromatography, ECD: Electron capture detector 


\section{Validation of analytical methods}

\section{Linearity tests}

Linearity tests were performed with fenpropathrin at 20, 25, 30, 35,40 , and $45 \mathrm{ppb}$; lambda-cyhalothrin at 10, 15, 20, 25, 30, and 40 ppb; and chlorothalonil at $5,10,15,20,25$, and $30 \mathrm{ppb}$. Using plots of concentration versus area, the equations $y=583.57 x-4418.2(\mathrm{r}=0.9994)$, $y=187.4 x+12787$ ( $\mathrm{r}=0.9992)$, and $y=1061.7 x-177.8(\mathrm{r}=0.9993)$ were generated for the respective pesticides (Fig. 1).

\section{$L O D$ and $L O Q$}

LOD and LOQ values for fenpropathrin, lambda-cyhalothrin, and chlorothalonil were 1.36 and $4.58,1.45$ and 4.85 , and 1.12 and 3.73 ppb, respectively.

\section{Accuracy and precision tests}

The result of accuracy and precision test was summarized in Tables 2-7.

\section{Establishment of sample concentrations}

Extracted samples were analyzed using GC with an ECD. Analyses were performed in triplicate and no traces of pesticides were found in any of the samples (Table 8).

\section{DISCUSSION}

In the present study, we used GC-ECD instead of GC MS-MS because it has greater efficiency. Although GC-ECD is limited by the potential for the matrix to capture other electrons, the requirements of linearity were met in our analyses of fenpropathrin, lambda-cyhalothrin, and chlorothalonil, with $r \geq 0.9990$ in all cases [14].

LOD and LOQ of these analyses were $0.005 \mu \mathrm{g} / \mathrm{kg}$ and LOD $1.22 \mathrm{ppb}$, and these were better than in previous pesticide analyses of lettuces and oranges [14]. These LOD and LOQ values of the three pesticides indicate sufficient sensitivity of these analyses [14].

The present percentage RT and percentage VC values for the three pesticides were $70 \%-120 \%$ and $\leq 20 \%$, respectively, and fulfilled the associated criteria. However, accuracy values did not increase in these analyses, likely reflecting technical limitations such as variations in additions of standards to vegetables, manual shaking and durations of waiting times, or variations in vortexing during extraction and partition stages.

No pesticide traces were found in any of the present samples, although chromatogram peaks with retention times of 10.78-10.79 min were

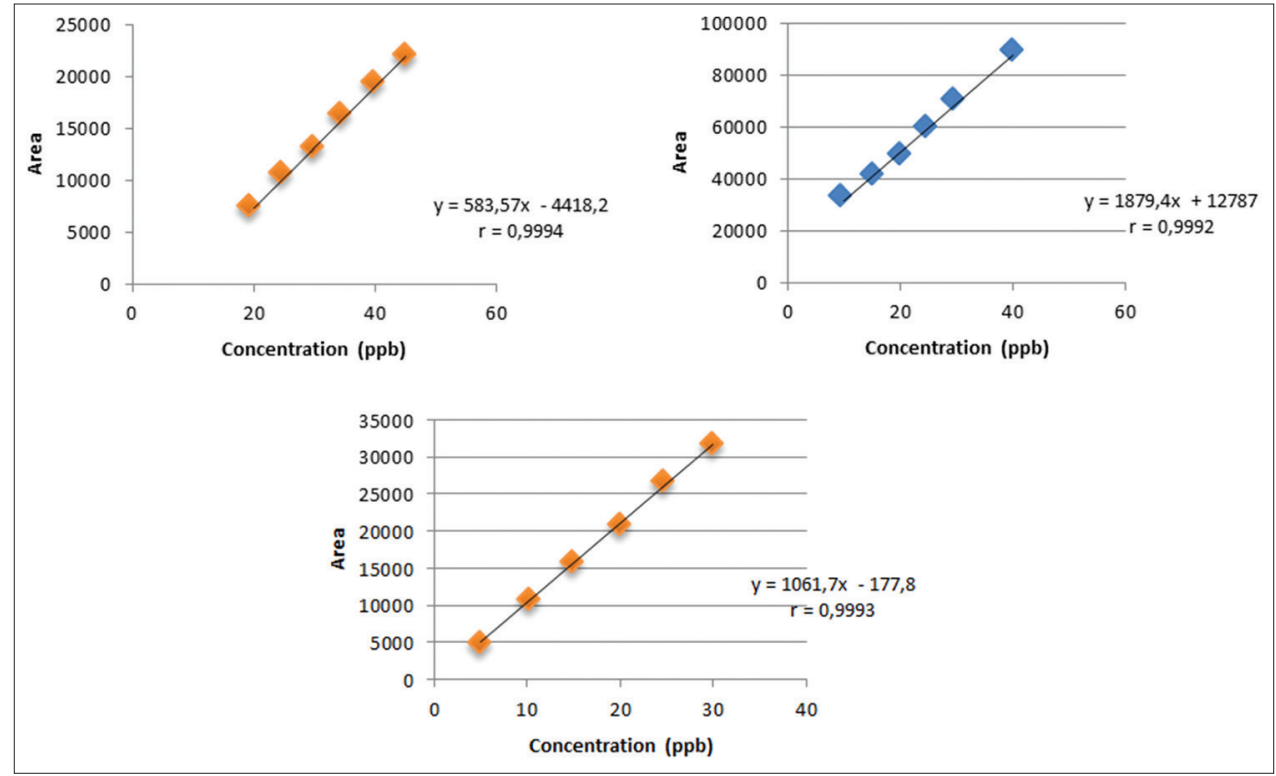

Fig. 1: Calibration curves of (a) fenpropathrin, (b) cyhalothrin, and (c) chlorothalonil

Table 2: Accuracy and precision tests for fenpropathrin in tomatoes

\begin{tabular}{|c|c|c|c|c|c|c|}
\hline $\begin{array}{l}\text { Standard } \\
\text { Concentration (ppb) }\end{array}$ & Area & $\begin{array}{l}\text { Standard } \\
\text { Measurement (ppb) }\end{array}$ & RT (\%) & $\overline{\mathbf{x}}$ & SD (\%) & (VC) (\%) \\
\hline \multirow[t]{6}{*}{20} & 8231.9 & 21.677 & 108.386 & 100.861 & 0.953 & 0.945 \\
\hline & 6916.6 & 19.423 & 97.116 & & & \\
\hline & 6708.1 & 19.066 & 95.330 & & & \\
\hline & 7589.4 & 20.576 & 102.880 & & & \\
\hline & 7102.1 & 19.741 & 98.705 & & & \\
\hline & 7574.2 & 20.550 & 102.750 & & & \\
\hline \multirow[t]{6}{*}{35} & 12754.8 & 29.427 & 84.079 & 86.819 & 3.295 & 3.795 \\
\hline & 13255.4 & 30.285 & 86.529 & & & \\
\hline & 13612.6 & 30.897 & 88.278 & & & \\
\hline & 13965.3 & 31.502 & 90.005 & & & \\
\hline & 12318.5 & 28.680 & 81.942 & & & \\
\hline & 13980.2 & 31.527 & 90.078 & & & \\
\hline \multirow[t]{6}{*}{45} & 15891.5 & 34.803 & 77.339 & 79.124 & 4.035 & 5.099 \\
\hline & 15498.6 & 34.129 & 75.843 & & & \\
\hline & 15684.7 & 34.448 & 76.551 & & & \\
\hline & 16627.1 & 36.063 & 80.140 & & & \\
\hline & 16087 & 35.138 & 78.083 & & & \\
\hline & 18372.3 & 39.054 & 86.786 & & & \\
\hline
\end{tabular}


Table 3: Accuracy and precision tests for fenpropathrin in potatoes

\begin{tabular}{|c|c|c|c|c|c|c|}
\hline $\begin{array}{l}\text { Standard } \\
\text { concentration (ppb) }\end{array}$ & Area & $\begin{array}{l}\text { Standard } \\
\text { measurement (ppb) }\end{array}$ & RT (\%) & $\overline{\mathbf{x}}$ & SD (\%) & $(\mathrm{VC})(\%)$ \\
\hline \multirow[t]{6}{*}{20} & 6496.8 & 18.704 & 93.519 & 96.725 & 0.518 & 0.536 \\
\hline & 6617 & 18.910 & 94.549 & & & \\
\hline & 6849.1 & 19.308 & 96.538 & & & \\
\hline & 6909 & 19.410 & 97.051 & & & \\
\hline & 7354.9 & 20.174 & 100.871 & & & \\
\hline & 6998.8 & 19.564 & 97.820 & & & \\
\hline \multirow{5}{*}{35} & 12329.3 & 28.698 & 81.995 & & & \\
\hline & 13250.9 & 30.278 & 86.507 & & & \\
\hline & 13668.3 & 30.993 & 88.551 & & & \\
\hline & 13216.8 & 30.219 & 86.340 & & & \\
\hline & 12118.8 & 28.338 & 80.965 & & & \\
\hline \multirow[t]{4}{*}{45} & 17440.2 & 37.456 & 83.236 & 85.779 & 0.882 & 1.028 \\
\hline & 18176.9 & 38.719 & 86.042 & & & \\
\hline & 18380.3 & 39.067 & 86.816 & & & \\
\hline & 18515.2 & 39.298 & 87.330 & & & \\
\hline
\end{tabular}

Table 4: Accuracy and precision tests for Lambda-Cyhalothrin in Tomatoes

\begin{tabular}{|c|c|c|c|c|c|c|}
\hline $\begin{array}{l}\text { Standard } \\
\text { Concentration (ppb) }\end{array}$ & Area & $\begin{array}{l}\text { Standard } \\
\text { Measurement (ppb) }\end{array}$ & RT (\%) & $\overline{\mathbf{x}}$ & SD (\%) & $(\mathrm{VC})(\%)$ \\
\hline \multirow[t]{6}{*}{10} & 29410.4 & 8.845 & 88.451 & 93.095 & 1.305 & 1.401 \\
\hline & 31155.9 & 9.774 & 97.738 & & & \\
\hline & 34845.6 & 11.737 & 117.370 & & & \\
\hline & 28184.9 & 8.193 & 81.930 & & & \\
\hline & 29421.6 & 8.8510 & 88.510 & & & \\
\hline & 28680.7 & 8.458 & 84.568 & & & \\
\hline \multirow{5}{*}{25} & 50397.5 & 20.012 & 80.048 & & & \\
\hline & 59506.5 & 24.859 & 99.435 & & & \\
\hline & 60362.7 & 25.314 & 101.257 & & & \\
\hline & 59458.4 & 24.833 & 99.333 & & & \\
\hline & 58407.4 & 24.274 & 97.096 & & & \\
\hline \multirow[t]{5}{*}{40} & 73764.7 & 32.445 & 81.113 & 82.810 & 1.740 & 2.101 \\
\hline & 74468.1 & 32.820 & 82.049 & & & \\
\hline & 77827 & 34.607 & 86.517 & & & \\
\hline & 72799 & 31.931 & 79.829 & & & \\
\hline & 80044.3 & 35.787 & 89.467 & & & \\
\hline
\end{tabular}

Table 5: Accuracy and precision tests for Lambda-Cyhalothrin in Potatoes

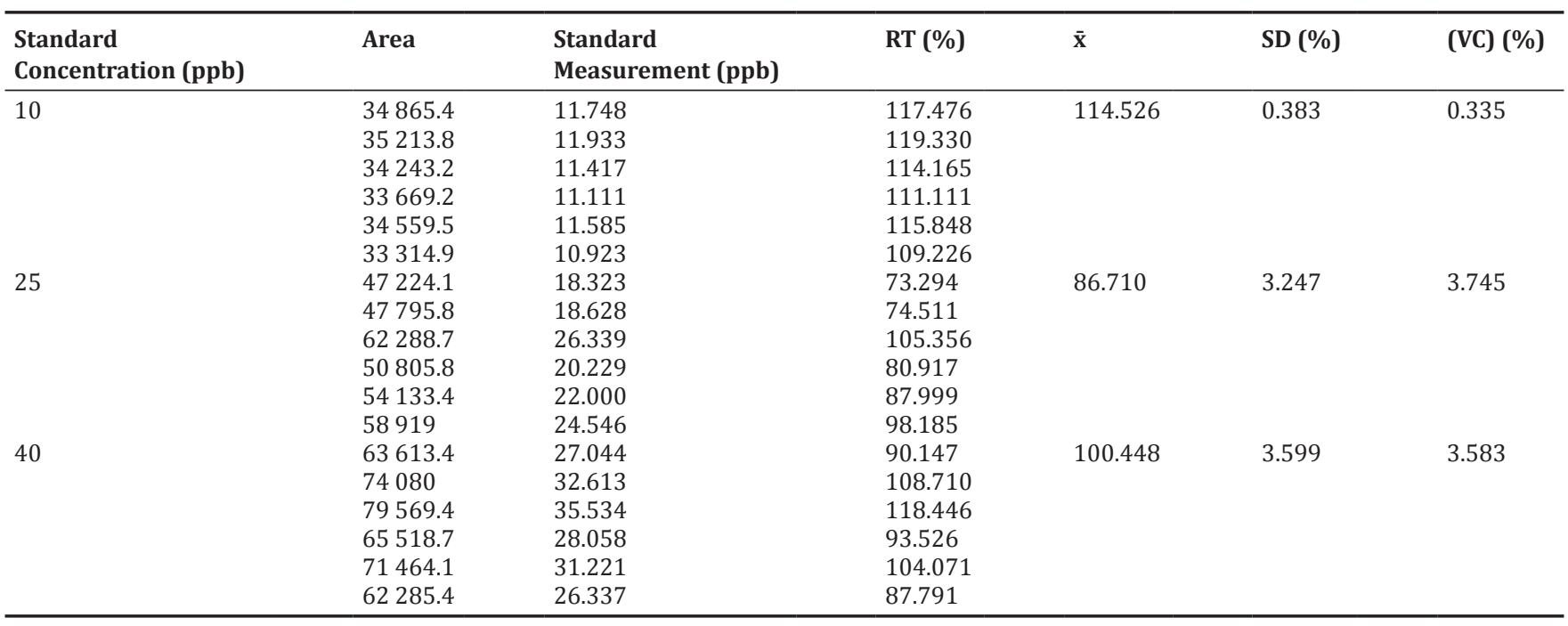


Table 6: Accuracy and precision tests for Cyhalothrin in tomatoes

\begin{tabular}{|c|c|c|c|c|c|c|}
\hline $\begin{array}{l}\text { Standard } \\
\text { Concentration (ppb) }\end{array}$ & Area & $\begin{array}{l}\text { Standard } \\
\text { Measurement (ppb) }\end{array}$ & RT (\%) & $\overline{\mathbf{x}}$ & SD (\%) & (VC) (\%) \\
\hline \multirow[t]{6}{*}{5} & 4465.9 & 4.374 & 87.477 & 97.288 & 0.3604 & 0.370 \\
\hline & 5300.4 & 5.160 & 103.197 & & & \\
\hline & 4622.2 & 4.521 & 90.421 & & & \\
\hline & 4954.4 & 4.834 & 96.679 & & & \\
\hline & 5440.7 & 5.292 & 105.840 & & & \\
\hline & 5136.7 & 5.006 & 100.113 & & & \\
\hline \multirow{5}{*}{20} & 16439.5 & 15.651 & 78.258 & & & \\
\hline & 15134.9 & 14.423 & 72.114 & & & \\
\hline & 18136.8 & 17.250 & 86.251 & & & \\
\hline & 17319.6 & 16.481 & 82.403 & & & \\
\hline & 16106.8 & 15.338 & 76.691 & & & \\
\hline \multirow[t]{4}{*}{30} & 23581.2 & 22.378 & 74.594 & 83.108 & 1.991 & 2.397 \\
\hline & 25828.6 & 24.495 & 81.650 & & & \\
\hline & 27123.5 & 25.715 & 85.716 & & & \\
\hline & 24740 & 23.470 & 78.232 & & & \\
\hline
\end{tabular}

Table 7: Accuracy and precision tests for Cyhalothrin in potatoes

\begin{tabular}{|c|c|c|c|c|c|c|}
\hline $\begin{array}{l}\text { Standard } \\
\text { Concentration (ppb) }\end{array}$ & Area & $\begin{array}{l}\text { Standard } \\
\text { measurement (ppb) }\end{array}$ & RT (\%) & $\overline{\mathbf{x}}$ & SD (\%) & (VC) (\%) \\
\hline \multirow[t]{6}{*}{5} & 4439.2 & 4.349 & 86.974 & 84.884 & 0.354 & 0.417 \\
\hline & 4366.3 & 4.280 & 85.600 & & & \\
\hline & 3834.5 & 3.779 & 75.583 & & & \\
\hline & 3938.6 & 3.877 & 77.546 & & & \\
\hline & 4813.2 & 4.701 & 94.019 & & & \\
\hline & 4577.7 & 4.479 & 89.583 & & & \\
\hline \multirow{5}{*}{20} & 16132.8 & 15.363 & 76.814 & & & \\
\hline & 18476.2 & 17.570 & 87.850 & & & \\
\hline & 15191.5 & 14.476 & 72.381 & & & \\
\hline & 17718.8 & 16.857 & 84.283 & & & \\
\hline & 16966.3 & 16.148 & 80.740 & & & \\
\hline \multirow[t]{5}{*}{30} & 23586.5 & 22.383 & 74.611 & 78.605 & 1.929 & 2.454 \\
\hline & 23213.1 & 22.032 & 73.439 & & & \\
\hline & 24066 & 22.835 & 76.116 & & & \\
\hline & 24407 & 23.157 & 77.187 & & & \\
\hline & 25050.3 & 23.762 & 79.206 & & & \\
\hline
\end{tabular}

Table 8: Analyses of fenpropathrin, lambda-cyhalothrin, and chlorothalonil contents in tomatoes and potatoes

\begin{tabular}{llll}
\hline Commodities & Notes & Fenpropathrin & Lambda-Cyhalothrin \\
\hline Potatoes & Depok & Undetected & Undetected \\
& Jakarta & Undetected & Undetected \\
& Tangerang & Undetected & Undetected \\
& Organic B & Undetected & Undetected \\
& Organic H & Undetected & Undetected \\
& Organic S & Undetected & Undetected \\
Depok & Undetected & Undetected \\
Tomatoes & Undetected & Undetected \\
& Tanarta & Undetected & Undetected \\
& Organic O & Undetected & Undetected \\
& Organic P & Undetected & Undeteded \\
& Organic S & Undetected & Undetected \\
\hline
\end{tabular}

observed from several of the tomato and potato samples. This retention time range was similar to that of chlorothalonil (10.82-10.84) but was sufficiently different to conclude that the undefined peaks were not chromatogram peaks of chlorothalonil and were likely due to matrix components.

\section{CONCLUSION}

Our linearity tests showed that all standards met the requirement of $r \geq 0.9990$, and these were applicable to fenpropathrin, lambdacyhalothrin, and chlorothalonil concentration ranges of 20-45 ppb, 
10-40 ppb, and 5-30 ppb, respectively. LOD and LOQ values for fenpropathrin, lambda-cyhalothrin, and chlorothalonil were similar to those reported by Lozano et al. and indicated high sensitivity of analyses $[12,13]$. Accuracy and precision values also fulfilled the requirements, furthervalidating of the methods used in this study. Finally, all samples fulfilled the requirements of SNI 7313: 2008 "Maximum Limit of Pesticides Residual Products in Harvest Commodities" and the other terms and conditions of Japanese standards.

\section{CONFLICTS OF INTEREST}

All authors declare that they have no conflicts of interest.

\section{REFERENCES}

1. Sudarmo S. Pesticide. Jogjakarta: Karnisius; 1991.

2. Indonesian Ministry of Agriculture. Regulation of Indonesian Ministry of Agriculture No. 39/Permentan/SR.330/7/2015 about Pesticide Registration. Jakarta, Indonesia; 2015.

3. Beard J. DDT and human health. Sci Total Environ 2006;355:78-89.

4. Haschek WM, Rousseaux CG, Wallig MA. Haschek and Rousseaux's Handbook of Toxicologic pathology. $3^{\text {rd }}$ ed. San Diego: Elsevier Inc.; 2013.

5. Fertilizer and Pesticide Directorate. Agriculture and Forestry Pesticide 2016. Jakarta: Ministry of Forestry; 2016

6. Williams PL, James RC, Roberts SM. Principle of Toxicology. $2^{\text {nd }}$ ed. New York: John Wiley and Sons Inc.; 2000.

7. Yua X, Ang HC, Yang $\mathrm{H}$, Zheng $\mathrm{C}$, Zhang Y. Low temperature cleanup combined with magnetic nanoparticle extraction to determine pyrethroids residue in vegetables oils. Food Control 2017;74:112-20.

8. de Moraes PM, Milantônio RB, Cagnani GS, Dos Santos FA, Padilha CD, de Lima PM, et al. Analytical procedure based on slurry sampling for determining selenium in organic vegetable samples by graphite furnace atomic absorption spectrometry. Eur Food Res Technol 2009;229:409-14

9. Yu X, Yang H. Pyrethroid residue determination in organic and conventional vegetables using liquid-solid extraction coupled with magnetic solid phase extraction based on polystyrene-coated magnetic nanoparticles. Food Chem 2017;217:303-10.

10. Sravanthi J, Gangadhar RS. Quantification of antioxidantphytochemical studies in Vitis vinifera L. Varieties. Asian J Pharm Clin Res 2015;8:295-301.

11. Venkatesh R, Shanthi S, Rajapandian K, Elamathi S, Thenmozhi S, Radha N. Preminary study on antixanthomonas activity, phytochemical analysis, and characterization of antimicrobial compounds from Kappaphycus alvarezii. Asian J Pharm Clin Res 2011;4:46-51.

12. Chauhan SS, Agrawal S, Srivastava A. Effect of imidacloprid insecticide residue on biochemical parameters in potatoes and its estimation by HPLC. Asian J Pharm Clin Res 2013;6:114-7.

13. Lozano A, Kiedrowska B, Scholten J, de Kroon M, de Kok A, Fernández-Alba AR. Miniaturisation and optimisation of the Dutch mini-Luke extraction method for implementation in the routine multiresidue analysis of pesticides in fruits and vegetables. Food Chem 2016;192:668-1.

14. Harmita AP. Physicochemistry Analysis Text Book. Depok: Pharmacy, Universitas Indonesia; 2006 